\title{
The Influence of Neoadjuvant Chemotherapy with Docetaxel, Nedaplatin and 5-Fluorouracil After Esophagectomy
}

\author{
SHINICHI ASAKA, TAKESHI SHIMAKAWA, KENTARO YAMAGUCHI, MINORU MURAYAMA, \\ ASAKO SHIMAZAKI, TAKAO KATSUBE and YOSHIHIKO NARITAKA \\ Department of Surgery, Tokyo Women's Medical University Medical Center East, Tokyo, Japan
}

\begin{abstract}
Background: Neoadjuvant chemotherapy (NAC) with docetaxel, nedaplatin and 5-fluorouracil (5-FU) in esophageal cancer may adversely affect the postoperative clinical course following esophagectomy. Patients and Methods: We investigated the perioperative white blood cell count (WBC), C-reactive protein (CRP), serum albumin, body temperature $(B T)$, heart rate $(H R)$, respiratory rate $(R R)$, water balance, partial pressure of oxygen in arterial blood $\left(\mathrm{PaO}_{2}\right) /$ fraction of inspired oxygen $\left(\mathrm{FiO}_{2}\right)$ ratio, postoperative complications and systemic inflammatory response syndrome (SIRS) in patients who underwent NAC or surgery alone (SA group). Results: In the NAC group, the preoperative WBC $(p=0.015)$ and postoperative day $(P O D)$ $3 B T(p=0.049)$, as well as $R R(p=0.037)$ were lower, whereas the POD $2 \mathrm{PaO}_{2} / \mathrm{FiO}_{2}$ ratio was higher $(p=0.047)$, compared to the SA group. No differences in the incidence of postoperative complications and SIRS were observed between the groups. Conclusion: NAC using docetaxel, nedaplatin and 5-fluorouracil was tolerated and feasible in esophageal cancer.
\end{abstract}

Recent advances in surgical techniques, postoperative care and treatment strategies have improved the surgical outcome of esophageal cancer. Recently, the utility of neoadjuvant chemotherapy (1-3) and chemoradiotherapy (4-7) for esophageal cancer was reported. In Japan, the usefulness of preoperative chemotherapy with cisplatin and 5-fluorouracil (5-FU) (CF) in cStage II/III esophageal cancer was shown in the JCOG9907 (8). However, it was also reported that preoperative treatment, particularly chemoradiotherapy, may

Correspondence to: Shinichi Asaka, MD, Department of Surgery, Tokyo Women's Medical University Medical Center East, 2-1-10 Nishiogu Arakawa-ku, Tokyo 116-8567, Japan. Tel: +81 338101111, Fax: +81 338945493, e-mail: sasaka225@yahoo.co.jp

Key Words: Neoadjuvant chemotherapy, esophageal cancer, postoperative complications. have adverse perioperative effects, such as increased postoperative complications (9-12). A recent study reported that preoperative chemotherapy with docetaxel, cisplatin and 5-FU (DCF) showed a survival benefit for esophageal cancer compared to $\mathrm{CF}(13,14)$. However, DCF may adversely affect the perioperative condition of esophageal cancer patients because of adverse events, such as hematological toxicity. Therefore, there is a concern that preoperative chemotherapy using DCF may influence the postoperative course after esophagectomy.

Esophagectomy is one of the most invasive surgical procedures in gastrointestinal surgery. It is known that surgical stress induces various biological reactions, such as neuroendocrine response, which is regulated by adrenocortical and adrenomedually hormones, and cytokine responses involving inflammatory mediators (such as tumor necrosis factor (TNF) $\alpha$, interleukin (IL)-1 $\beta$, IL-6, IL-12 and IL-18) (15) and anti-inflammatory mediators (16), which are activated to maintain physiological homeostasis $(17,18)$. Increased heart rate (HR), body temperature (BT), respiratory rate (RR), white blood cell (WBC) and C-reactive protein (CRP) levels result from these various responses in the neuroendocrine, cardiovascular, metabolic and immunological systems. In addition, hypercytokinemia may subsequently lead to development of systemic inflammatory syndrome (SIRS), followed by the compensatory anti-inflammatory response syndrome (CARS) (19). SIRS often leads to organ dysfunction, such as acute lung injury (ALI) (20) and increases postoperative complications (21). Furthermore, multiple organ failure (MOF) may occur after a longer duration of SIRS (21). Therefore, it is important to control the inflammatory response to perform perioperative care safely. In particular, preventing ALI is important because it decreases the partial pressure of oxygen in arterial blood $\left(\mathrm{PaO}_{2}\right)$ /fraction of inspired oxygen $\left(\mathrm{FiO}_{2}\right)$ ratio and may cause severe complications in patients.

Although preoperative chemotherapy with DCF may influence these biological reactions and the postoperative clinical course because of adverse events, such as 
hematological toxicity, no previous study has assessed this in detail. The aim of this study was to clarify whether NAC increases the risk of pulmonary dysfunction, the incidence of SIRS and complications after surgery. We investigated the postoperative course based on biological parameters (HR, $\mathrm{BT}, \mathrm{RR}, \mathrm{WBC}$ and $\mathrm{CRP}$ ), $\mathrm{PaO}_{2} / \mathrm{FiO}_{2}$ ratio and the incidence and duration of SIRS, as well as postoperative complications between patients who underwent NAC following surgery or surgery alone.

\section{Patients and Methods}

Patients. A retrospective study was performed in 50 consecutive patients who underwent transthoracic esophagectomy for cT3, cN01 or cM0 thoracic esophageal cancer at the Tokyo Women's Medical University Medical Center East between 2008 and 2013. Eighteen patients received NAC followed by surgery (NAC group) and 32 underwent surgery alone (SA group). The surgical procedures included transthoracic esophagectomy via a right fifth or sixth thoracotomy, left sixth thoracotomy, cervical esophagogastrotomy via the antethoracic, retrosternal or posterior mediastinal route with a two- or three-fold lymphadenectomy. Patients' data were retrospectively evaluated using all medical and nursing charts, including preoperative status, surgical procedures and the perioperative systemic response, including $\mathrm{BT}, \mathrm{RR}, \mathrm{HR}$, water balance, WBC, serum CRP level, serum albumin level, $\mathrm{FiO}_{2} / \mathrm{PaO}_{2}$ ratio, the incidence and duration of SIRS by postoperative day (POD) 4 and the incidence of postoperative complications. Moreover, we calculated the surgical stress score (SSS), as previously described (22), to compare the surgical stress between the two groups.

At the end of the operation, all patients were admitted to the intensive care unit (ICU) and ventilated using Evita XL respirators (Dräger Medical, Lübeck, Germany) equipped with an automated weaning system SmartCare/PS version 1.1; they were extubated on POD 2. Methylprednisolone sodium succinate $(5 \mathrm{mg} / \mathrm{kg})$ was used at the start of surgery. A continuous intravenous (i.v.) infusion of $4.8 \mathrm{mg} / \mathrm{kg}$ /day sivelestat sodium hydrate was used from the end of surgery until POD 2.

SIRS was diagnosed according to the criteria proposed by the American College of Chest Physicians/Society of Critical Care Medicine Consensus Conference (23). SIRS was defined as two or more of the following: i) $\mathrm{BT}>38^{\circ} \mathrm{Cor}<36^{\circ} \mathrm{C}$, ii) $\mathrm{HR}>90$ beats $/ \mathrm{min}$, iii) $\mathrm{RR}>20$ beats/minor $\mathrm{PaCO} 2<32$ torr and iv) $\mathrm{WBC}$ count $>12,000$ or $<4,000$ cells $/ \mathrm{mm}^{3}$ or $>10 \%$ immature band forms.

Postoperative complications included non-infectious complications, such as recurrent nerve paralysis, atrial fibrillation, delirium and hepatic dysfunction (glutamic oxaloacetic transaminase (GOT) or glutamate pyruvate transaminase (GPT) $\leq 200$ or hyperbilirubinemia (total bilirubin $\leq 3.0$ )), infectious complications, such as pneumonia, anastomosis leakage, surgical site infection (SSI), sepsis, central vein catheter infection and enteritis. Pneumonia was defined as respiratory symptoms, opacity in a plain chest X-ray and detection of pathogenic bacteria in sputum cultures. Postoperative complications were only included in the study when patients had a Clavien-Dindo classification $>\mathrm{I}$ (24).

NAC. NAC consisted of a 1-h i.v. infusion of $50 \mathrm{mg} / \mathrm{m}^{2}$ docetaxel on day 1, a 2-h infusion of $12 \mathrm{mg} / \mathrm{m}^{2} /$ day nedaplatin on days $1-5$ and continuous i.v. infusion of $500 \mathrm{mg} / \mathrm{m}^{2} /$ day $5-\mathrm{FU}$ on days 1-5. A second cycle of NAC was administered 3-4 weeks after the first cycle. Computed tomography (CT), upper gastrointestinal endoscopy and esophagography were performed approximately 2 weeks after each treatment cycle to assess efficacy, according to RECIST version 1.1 (25).

Statistical analysis. The data are expressed as means \pm SEM. Statistical analyses were performed using Student's $t$-tests, Chi-squared tests and Fisher's exact tests. $p$-Values $<0.05$ were considered to be statistically significant. All analyses were performed using the JMP version 11 (SAS Institute, Inc., Cary, NC, USA).

\section{Results}

Patients. No differences were observed in age, gender or bodyweight between the two groups. Tumor diameter was significantly larger in the NAC group $(81 \pm 35.2 \mathrm{~mm})$ compared to the SA group $(55.2 \pm 17.1 \mathrm{~mm})(p=0.0013)$. Esophagogastrectomy via the posterior mediastinal route and three-region lymph node dissection were performed more frequently in the NAC group than in the SA group. The pathological assessment of tumor samples revealed no significant difference in tumor depth, lymph node metastasis, TNM classification or residual tumor volume between the treatment groups. There was no significant difference in surgical time; however, blood loss was significantly greater in the NAC group $(927.5 \pm 591.5 \mathrm{ml})$ compared to that in the SA group $(460.8 \pm 198.7 \mathrm{ml})(p=0.00027)$. Therefore, SSS was significantly higher in the NAC group compared with the SA group $(0.879 \pm 0.126 v s .0 .752 \pm 0.069 ; p=0.00005)$. There was no significant difference in preoperative pulmonary function and/or ventilation time (Table I).

Laboratory data. The preoperative WBC count was significantly lower in the NAC group than in the SA group $(5,911 \pm 1,308 v s .7,275 \pm 2,027 ; p=0.015)$. The postoperative WBC count in the NAC group was also less than in the SA group until POD 3, although not significantly. The serum CRP and albumin levels were lower in the NAC group compared with the SA group, although not significantly (Figure 1). BT in the NAC group was lower until POD 4, which was significant on POD 3 (37.1 0.3 vs. $37.4 \pm 0.5$; $p=0.049)$ compared with that in the $\mathrm{SA}$ group. RR was also lower in the NAC group, which was again significant on POD 3 (23.2 \pm 2.3 vs. 25.2 $2.3 ; p=0.037)$. There was no difference in HR between the groups until POD 3; it was, however, increased in the NAC group after POD 4. In both groups, the water balance was negative on POD 2 but returned to positive on POD 4; no significant differences were observed during the postoperative course (Figure 2).

There were no differences in the preoperative $\mathrm{PaO}_{2} / \mathrm{FiO}_{2}$ ratio between the two groups. The $\mathrm{PaO}_{2} / \mathrm{FiO}_{2}$ ratio decreased after surgery in both groups; however, the decrease was smaller in the NAC group compared with that in the SA 
Table I. Patients' and tumors' characteristics.

\begin{tabular}{|c|c|c|c|}
\hline & $\begin{array}{c}\mathrm{NAC} \\
(\mathrm{n}=18)\end{array}$ & $\begin{array}{l}\text { Surgery alone } \\
\quad(\mathrm{n}=32)\end{array}$ & $p$-Value \\
\hline Age & $69.2 \pm 6.4$ & $68.8 \pm 9.2$ & $0.898^{\ddagger}$ \\
\hline Male/female & $15 / 3$ & $30 / 2$ & \\
\hline Body Weight (kg) & $54.7 \pm 10.1$ & $56.5 \pm 10.7$ & $0.574^{*}$ \\
\hline$\% \mathrm{VC}$ & $105.1 \pm 20.2$ & $104.2 \pm 16.2$ & $0.878^{\ddagger}$ \\
\hline FEV1.0 & $74.6 \pm 11.5$ & $76.4 \pm 10.8$ & $0.603 \ddagger$ \\
\hline Tumor location & & & $0.165^{*}$ \\
\hline Upper & 1 & 2 & \\
\hline Middle & 12 & 13 & \\
\hline Lower & 5 & 17 & \\
\hline Tumor size (mm) & $81.0 \pm 35.2$ & $55.2 \pm 17.1$ & $0.001 *$ \\
\hline $20-39$ & 1 & 4 & \\
\hline $40-59$ & 4 & 14 & \\
\hline $60-79$ & 2 & 12 & \\
\hline 80- & 11 & 2 & \\
\hline pT & & & $0.095^{*}$ \\
\hline $1 \mathrm{~b}$ & 2 & 0 & \\
\hline 2 & 2 & 2 & \\
\hline 3 & 9 & 27 & \\
\hline 4 & 3 & 3 & \\
\hline $\mathrm{pN}$ & & & $0.304^{*}$ \\
\hline 0 & 7 & 8 & \\
\hline 1 & 11 & 24 & \\
\hline $\mathrm{pM}$ & & & $0.239^{\dagger}$ \\
\hline 0 & 15 & 30 & \\
\hline $1 \mathrm{~b}$ & 3 & 2 & \\
\hline Pathological stage & & & $0.622 *$ \\
\hline I & 1 & 0 & \\
\hline IIA & 3 & 9 & \\
\hline IIB & 1 & 1 & \\
\hline III & 10 & 20 & \\
\hline IVB & 1 & 2 & \\
\hline Reconstruction route & & & $0.011 *$ \\
\hline Antethoracic & 1 & 1 & \\
\hline Retrosternal & 16 & 16 & \\
\hline Posterior mediastinal & 1 & 15 & \\
\hline Transthoracic esophagectomy & & & $1.000^{\dagger}$ \\
\hline $\mathrm{R}$ & 17 & 31 & \\
\hline $\mathrm{L}$ & 1 & 1 & \\
\hline Fields of lymphadenectomy & & & $0.064^{\dagger}$ \\
\hline 2 & 3 & 15 & \\
\hline 3 & 15 & 17 & \\
\hline Residual tumor (\%) & $83.3 \%$ & $81.3 \%$ & $1.000^{\dagger}$ \\
\hline R0 & 15 & 26 & \\
\hline $\mathrm{R} 1 / \mathrm{R} 2$ & 3 & 6 & \\
\hline Operation time (min) & $443.0 \pm 62.8$ & $426.1 \pm 73.2$ & $0.423^{\ddagger}$ \\
\hline Bleeding $(\mathrm{ml})$ & $927.5 \pm 591.5$ & $460.8 \pm 198.7$ & $<.001^{\ddagger}$ \\
\hline $\begin{array}{l}\text { Duration of ventilator } \\
\text { dependence (min) }\end{array}$ & $2992.8 \pm 39.4$ & $2994.8 \pm 69.2$ & $0.913^{\ddagger}$ \\
\hline
\end{tabular}

*Chi-square test. †Fisher's exact test. $¥$ Student’s $t$-test. NAC: neoadjuvant chemotherapy; FEV: forced expiratory volume. Data are given as mean $\pm \mathrm{SD}$.

group. In particular, the $\mathrm{PaO}_{2} / \mathrm{FiO}_{2}$ ratio was significantly higher in the NAC group on POD $2(369.2 \pm 55.9 \mathrm{vs}$. $325.5 \pm 78.5 ; p=0.047$ ) (Figure 2).
Postoperative complications. The postoperative complications are summarized in Table II. There were no differences in the frequency of infectious or non-infectious complications between the two groups. Although 12 patients had pneumonia, no cases required re-intubation or tracheotomy. Two patients in SA group had an astomotic leakage, which did not require re-operation. Apart from one patient in the NAC group who had Grade 3 recurrent laryngeal nerve palsy, all the reported cases of recurrent nerve paralysis were Grade 2 .

SIRS. No difference was observed in the postoperative frequency of SIRS between the two groups $(44.4 \%$ in the NAC group $v s .46 .9 \%$ in the SA group) (Table IIIA). The incidence of SIRS in the NAC group was $50 \%(3 / 6)$ in patients with infectious complications and $41.7 \%(5 / 12)$ in those with non-infectious complications. In the SA group, the incidence of SIRS was $63.6 \%(7 / 11)$ in patients with infectious complications, compared with $38.1 \%(8 / 21)$ in those with non-infectious complications. However, the duration of SIRS was significantly longer in NAC patients with infectious complications compared with SA patients with infectious complications $(98.7 \pm 30.2 \mathrm{~h} v s .48 .1 \pm 21.2 \mathrm{~h}$; $p=0.027$ ) (Table IIIB). In contrast, the duration of SIRS tended to be shorter in patients in the NAC group with noninfectious complications compared to those in the SA group (11.0 $\pm 7.0 \mathrm{~h}$ vs. $38.9 \pm 28.2 \mathrm{~h} ; p=0.07$ ) (Table IIIB). In the NAC group, the duration of SIRS was significantly longer in patients with infectious complications compared with those with non-infectious complications $(98.7 \pm 30.2 \mathrm{~h} v s .11 .0 \pm 7.0 \mathrm{~h}$; $p=0.002)$. However, there was no difference in the duration of SIRS between patients with infectious and non-infectious complications in the SA group $(48.1 \mathrm{~h} \pm 21.2 \mathrm{~h} v$ s. $38.9 \pm 28.2 \mathrm{~h}$; $p=0.52$ ).

\section{Discussion}

In the present study, we made two important clinical observations. First, the decrease in the $\mathrm{PaO}_{2} / \mathrm{FiO}_{2}$ ratio after surgery was suppressed in the NAC group and, significantly, on POD 2, despite of no difference in preoperative pulmonary dysfunction, $\mathrm{PaO}_{2} / \mathrm{FiO}_{2}$ ratio and the frequency of postoperative pneumonia between the groups. These findings suggest that excessive inflammatory responseinduced ALI was suppressed in the NAC group. It is known that monocytes and macrophages in the surgical site are activated to produce inflammatory cytokines, mainly IL-1, TNF $\alpha$ and IL-6, after a highly invasive surgery. The inflammatory cytokines then activate monocytes, neutrophils and vascular endothelial cells, which produce inflammatory mediators, such as chemokines, platelet activating factor (PAF), neutrophil elastase and free radicals. Tissue damage, damage to the vascular endothelium $(26,27)$ and microcirculatory disorders due to microthrombus formation 

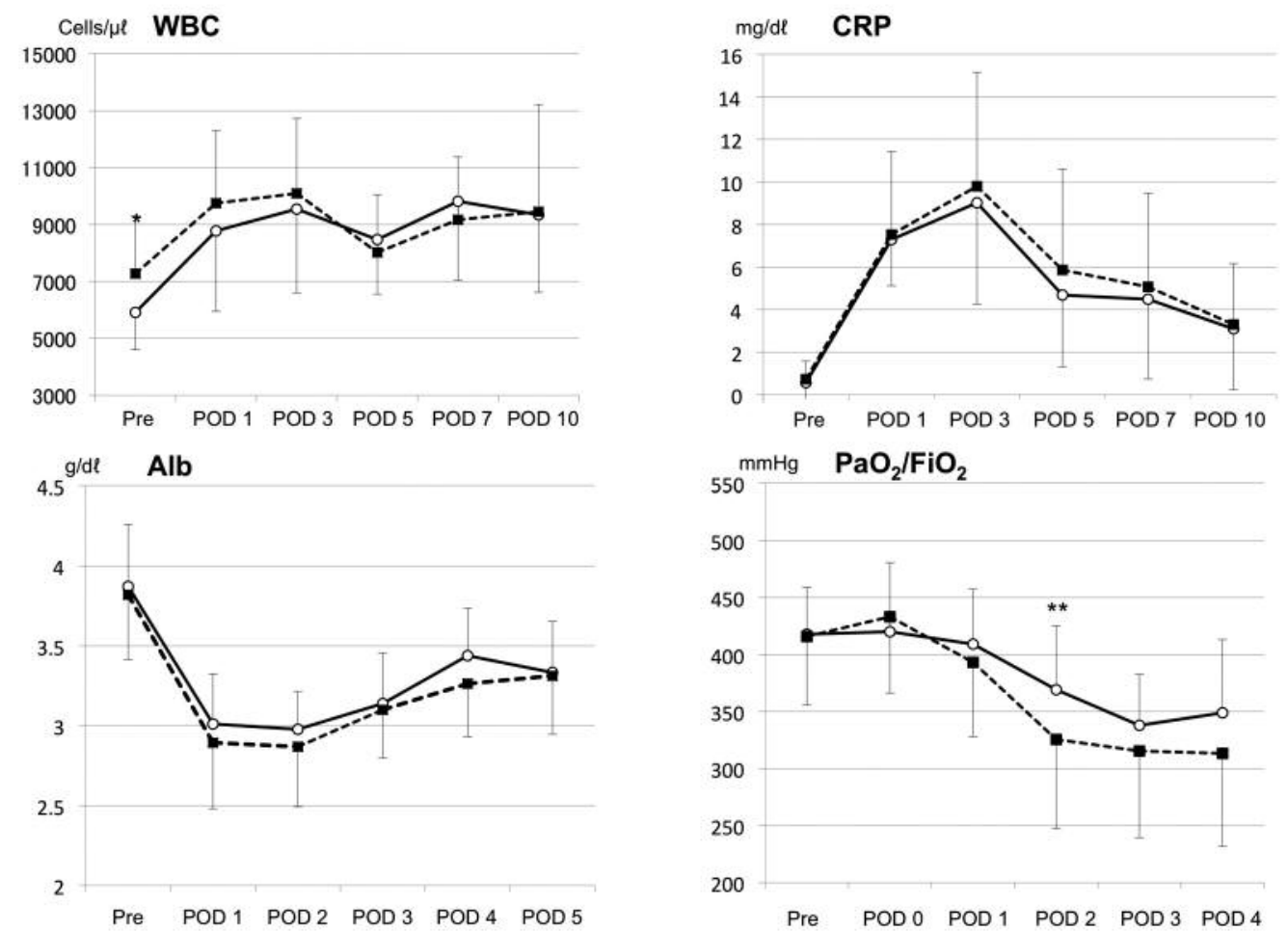

Figure 1. Postoperative changes in the WBC, CRP, Alb and $\mathrm{PaO}_{2} / \mathrm{FiO}_{2}$ ratio balance in the NAC group (O), as well as surgery alone (SA) group (ם). WBC, white blood cell count; $C R P, C$-reactive protein; Alb, serum albumin; $P O D$, postoperative day; $\mathrm{PaO}_{2} / \mathrm{FiO}_{2}$, partial pressure of oxygen in arterial blood/fraction of inspired oxygen. $* p=0.015, * * p=0.047$.

Table II. Postoperative complications.

\begin{tabular}{lccc}
\hline & $\begin{array}{c}\text { NAC } \\
(\mathrm{n}=18)\end{array}$ & $\begin{array}{c}\text { Surgery alone } \\
(\mathrm{n}=32)\end{array}$ & $p$-Value \\
\hline Infectious complication (\%) & $6(33.3)$ & $11(34.4)$ & $0.950^{\dagger}$ \\
$\quad$ Pneumonia & $4(22.2)$ & $8(25.0)$ & $1.000^{\dagger}$ \\
Anastomotic leakage & 0 & $2(6.3)$ & $0.039^{\dagger}$ \\
SSI & $3(16.7)$ & $3(9.4)$ & $0.654^{\dagger}$ \\
Sepsis & $1(5.6)$ & 0 & $0.360^{\dagger}$ \\
CV catheter infection & $1(5.6)$ & 0 & $0.360^{\dagger}$ \\
Infectious enteritis & 0 & $1(3.1)$ & $1.000^{\dagger}$ \\
Non-infectious complication (\%) & $13(72.2)$ & $21(65.6)$ & $0.631^{*}$ \\
Hepatic failure* & $3(16.7)$ & $12(37.5)$ & $0.199^{\dagger}$ \\
Recurrent laryngeal nerve palsy & $7(38.9)$ & $6(18.8)$ & $0.180^{*}$ \\
Arrythemia & $5(27.8)$ & $5(15.6)$ & $0.463^{*}$ \\
Delirium & $3(16.7)$ & $3(9.4)$ & $0.654^{\dagger}$ \\
\hline
\end{tabular}

$\dagger$ Fisher's exact test. *Chi-square test. *Hepatic failure: presence of one or more of the following: 1) serum AST or ALT > $200 \mathrm{IU}, 2)$ serum total bilirubin $(\mathrm{mg} / \mathrm{dl})>3.0$. NAC: neoadjuvant chemotherapy; SSI: surgical site infection; $\mathrm{CV}$ : central venous.

(28), which was caused by activated neutrophils, all lead to organ dysfunction. In the lungs, accumulation of activated neutrophils and neutrophil elastase damages lung capillary
Table III. Postoperative frequency and duration of SIRS.

\begin{tabular}{|c|c|c|c|}
\hline A All patients & $\begin{array}{l}\text { NAC } \\
(n=18)\end{array}$ & $\begin{array}{c}\text { Surgery alone } \\
\quad(\mathrm{n}=32)\end{array}$ & $p$-Value \\
\hline SIRS $(\%)$ & $8(44.4)$ & $15(46.9)$ & $0.869 *$ \\
\hline Duration of SIRS (h) & 43.875 & 43.2 & $0.966^{\ddagger}$ \\
\hline Range (h) & $4-120$ & $8-88$ & \\
\hline B Duration of SIRS (h) & $\begin{array}{l}\text { NAC } \\
(n=8)\end{array}$ & $\begin{array}{l}\text { Surgery alone } \\
\quad(\mathrm{n}=15)\end{array}$ & $p$-Value \\
\hline Infectious complication & $98.7 \pm 30.2$ & $48.1 \pm 21.2$ & $0.027 \ddagger$ \\
\hline Non-infectious complication & $11.0 \pm 7.0$ & $38.9 \pm 28.2$ & $0.072 \ddagger$ \\
\hline
\end{tabular}

*Chi-square test. $¥$ Student’s $t$-test. SIRS: systemic inflammatory response syndrome; NAC: neoadjuvant chemotherapy.

endothelial cells; this increases capillary permeability and, eventually, leads to pulmonary edema, resulting in ALI (29). Therefore, the production of cytokines may have been suppressed in the NAC group, preventing the progression of ALI. Consistent with this, BT and RR, which are affected by cytokines, such as IL-1, IL- 6 and TNF- $\alpha$, were lower in the 

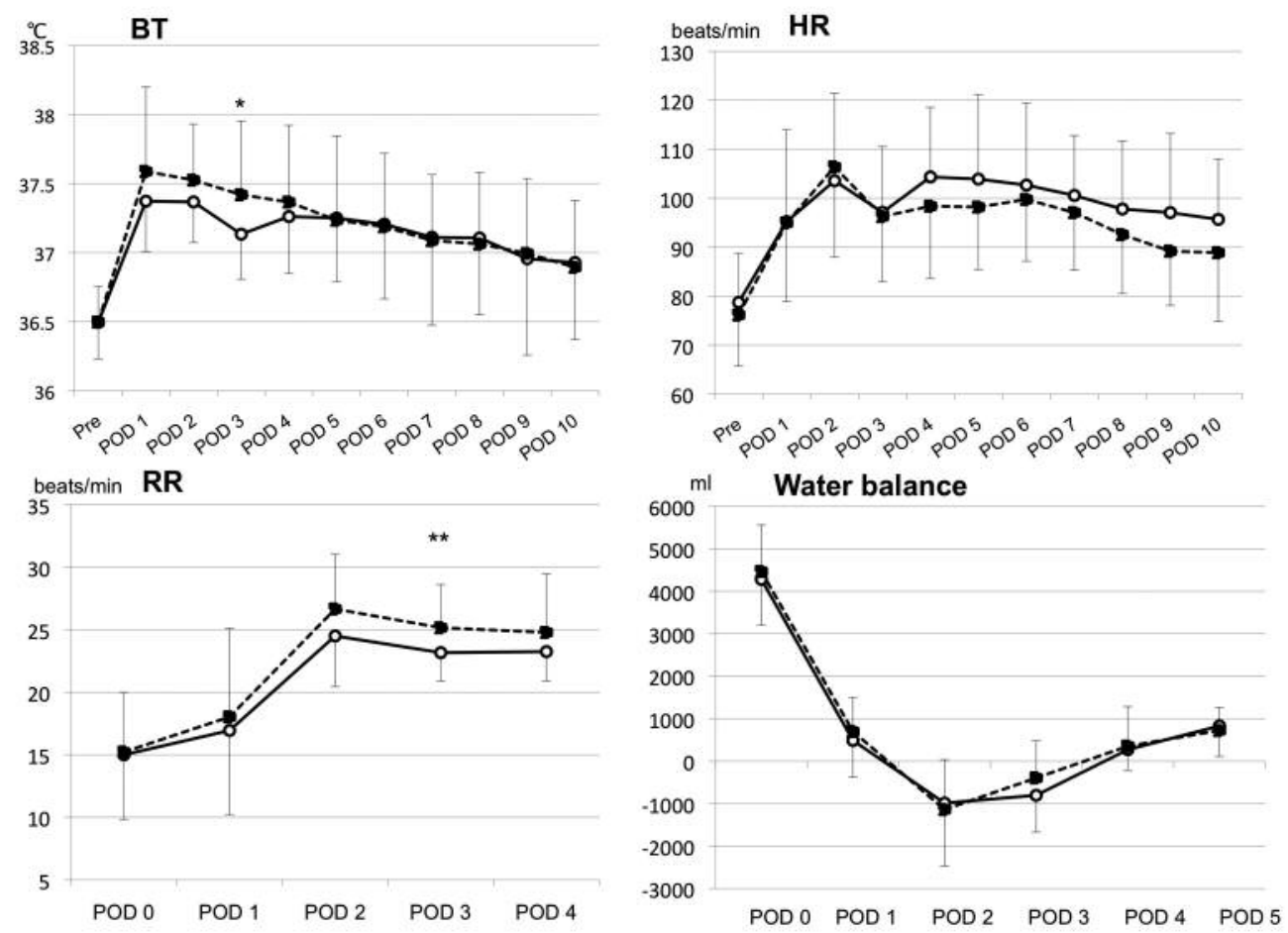

Figure 2. Postoperative changes in the BT, HR, RR and water balance in the NAC group (O), as well as surgery alone (SA) group (ם). BT, body temperature; HR, heart rate; $R R$, rspiratory rate; $P O D$, postoperative day. ${ }^{*} p=0.049$, ** $p=0.037$.

NAC group until POD 4 compared with that in the SA group, which was significant on POD 3.

The factors that could induce cytokine production after surgery are as follows: i) the number of cytokine-producing cells, ii) surgical stress and iii) anticytokine therapy. Regarding the number of cytokine-producing cells, the preoperative WBC in the NAC group was significantly less than that in the SA group. In addition, the postoperative WBC was lower in the NAC until POD 3, although not significantly. Therefore, it is possible that the number of inflammatory cells, such as neutrophils, monocytes and macrophages, was decreased in the NAC group because of insufficient recovery from hematological toxicity with chemotherapy.

During surgical stress, the cytokine concentration increases in proportion to the level of stress. Sakamoto et al. reported that blood IL-6 levels increased with the amount of blood loss and surgery time (30). In addition, Haga et al. demonstrated that the maximum postoperative CRP and duration of SIRS were significantly correlated with patients' original SSS, which is determined by the amount of blood loss, surgical time and extent of surgery (22). A higher SSS indicates increased inflammatory cytokine secretion. Since the amount of blood loss was significantly larger in the NAC group, despite a comparable surgical time, SSS was also significantly higher in the NAC group. This may have been caused by the larger tumor size and high frequency of threeregion lymph node dissection in NAC patients, which exposed them to increased stress. Based on surgical stress, acute lung injury could be expected to increase in NAC patients in general. However, our results suggest that cytokine production may have been suppressed in the NAC group, which may be due to a suppression of the cytokineproducing cells during NAC.

Although the efficacy of anticytokine therapy for ALI, such as the inhibition of inflammatory cytokines using steroids (31) and the inhibition of neutrophil elastase using protease inhibitors, has been reported in a number of studies (32-34), inflammatory cytokines are not completely inhibited by treatment alone. Since patients in both the NAC and SA groups, in the current study, underwent the same anticytokine therapy, this is unlikely to have affected the results.

Increased microvascular permeability is a common feature of ALI; therefore, serum albumin levels, which affect water balance and colloid osmotic pressure, may play a role in pulmonary vascular permeability during ALI. Therefore, we investigated serum albumin levels and the water balance after esophagectomy. However, there were no statistically 
significant differences in serum albumin levels or water balance between the two groups.

The second important clinical observation in the current study is that there was no difference in the frequency of SIRS or complications after surgery between the two groups. However, the duration of SIRS was significantly longer in NAC patients with infectious complications compared with SA patients with infectious complications, whereas the duration of SIRS in patients with non-infectious complications tended to be shorter in the NAC group compared with the SA group. Many previous studies reported no difference in the risk of preoperative chemotherapy-associated postoperative complications (3538). In contrast, Schlag et al. (12) reported a considerable increase in the incidence of postoperative complications, such as infections and acute respiratory distress syndrome (ARDS) in patients who underwent preoperative chemotherapy for squamous cell cancer of the esophagus. Furthermore, Tujimoto et al. (10) reported that NAC resulted in a longer duration and higher incidence of SIRS, although no differences were observed in the frequency of postoperative complications between the preoperative chemoradiotherapy (CRT) and SA groups. In addition, Haga et al. (21) reported that a longer duration of SIRS was associated with an increased number of complications. Because of these conflicting reports, the influence of NAC on the postoperative clinical course, including the incidence of complications and SIRS, remains controversial. In the current study, the longer duration of SIRS in NAC patients with infectious complications suggests that NAC may have negatively affected SIRS. Further investigation of this issue will be needed.

\section{References}

1 Bancewicz J, Clark PI, Smith DB, Donnelly RJ, Fayers PM, Weeden S and Girling DJ: Surgical resection with or without preoperative chemotherapy in oesophageal cancer. a randomised controlled trial. Lancet 359: 1727-1733, 2002.

2 Cunningham D, Allum WH, Stenning SP, Thompson JN, Van de Velde CJH, Nicolson M, Scarffe JH, Lofts FJ, Falk SJ, Iveson TJ, Smith DB, Langley RE, Verma M, Weeden S and Chua YJ: Perioperative chemotherapy versus surgery alone for resectable gastroesophageal cancer. N Engl J Med 355: 11-20, 2006.

3 Sjoquist KM, Burmeister BH, Smithers BM, Zalcberg JR, Simes RJ, Barbour A and Gebski V: Survival after neoadjuvant chemotherapy or chemoradiotherapy for resectable oesophageal carcinoma: an updated meta-analysis. Lancet Oncol 12: 681-692, 2011.

4 Tepper J, Krasna MJ, Niedzwiecki D, Hollis D, Reed CE, Goldberg R, Kiel K, Willett C, Sugarbaker D and Mayer R: Phase III trial of trimodality therapy with cisplatin, fluorouracil, radiotherapy, and surgery compared with surgery alone for esophageal cancer: CALGB 9781. J Clin Oncol 26: 1086-1092, 2008 .
5 Gebski V, Burmeister B, Smithers BM, Foo K, Zalcberg J and Simes J: Survival benefits from neoadjuvant chemoradiotherapy or chemotherapy in oesophageal carcinoma: a meta-analysis. Lancet Oncol 8: 226-234, 2007.

6 Urschel JD and Vasan H: A meta-analysis of randomized controlled trials that compared neoadjuvant chemoradiation and surgery to surgery alone for resectable esophageal cancer. Am J Surg 185: 538-543, 2003.

7 Walsh TN, Noonan N, Hollywood D, Kelly A, Keeling N and Hennessy TP: A comparison of multimodal therapy and surgery for esophageal adenocarcinoma. N Engl J Med 335: 462-467, 1996.

8 Ando N, Kato H, Igaki H, Shinoda M, Ozawa S, Shimizu H, Nakamura T, Yabusaki H, Aoyama N, Kurita A, Ikeda K, Kanda T, Tsujinaka T, Nakamura $\mathrm{K}$ and Fukuda $\mathrm{H}$ : A randomized trial comparing postoperative adjuvant chemotherapy with cisplatin and 5-fluorouracil versus preoperative chemotherapy for localized advanced squamous cell carcinoma of the thoracic esophagus (JCOG9907). Ann Surg Oncol 19: 68-74, 2012.

9 Reynolds JV, Ravi N, Hollywood D, Kennedy MJ, Rowley S, Ryan A, Hughes N, Carey M and Byrne P: Neoadjuvant chemoradiation may increase the risk of respiratory complications and sepsis after transthoracic esophagectomy. J Thorac Cardiovasc Surg 132: 549-555, 2006.

10 Tsujimoto H, Ono S, Chochi K, Sugasawa H, Ichikura T and Mochizuki H: Preoperative chemoradiotherapy for esophageal cancer enhances the postoperative systemic inflammatory response. Jpn J Clin Oncol 36: 632-637, 2006.

11 Fiorica F, Di Bona D, Schepis F, Licata A, Shahied L, Venturi $\mathrm{A}$, Falchi AM, Craxì $\mathrm{A}$ and Camma $\mathrm{C}$ : Preoperative chemoradiotherapy for oesophageal cancer: a systematic review and meta-analysis. Gut 53: 925-930, 2004.

12 Schlag PM: Randomized trial of preoperative chemotherapy for squamous cell cancer of the esophagus. The Chirurgische Arbeitsgemeinschaft Fuer Onkologie der Deutschen Gesellschaft Fuer Chirurgie Study Group. Arch Surg 127: 1446-50, 1992.

13 Watanabe M, Baba Y, Yoshida N, Ishimoto T, Nagai Y, Iwatsuki $\mathrm{M}$, Iwagami $\mathrm{S}$ and Baba $\mathrm{H}$ : Outcomes of preoperative chemotherapy with docetaxel, cisplatin, and 5-fluorouracil followed by esophagectomy in patients with resectable nodepositive esophageal cancer. Ann Surg Oncol 21: 2838-2844, 2014.

14 Hara H, Tahara M, Daiko H, Kato K, Igaki H, Kadowaki S, Tanaka Y, Hamamoto Y, Matsushita H, Nagase M and Hosoya Y: Phase II feasibility study of preoperative chemotherapy with docetaxel, cisplatin, and fluorouracil for esophageal squamous cell carcinoma. Cancer Sci 104: 1455-1460, 2013.

15 Raeburn CD, Sheppard F, Barsness KA, Arya J and Harken AH: Cytokines for surgeons. Am J Surg 183: 268-273, 2002.

16 Munford RS and Pugin J: Normal responses to injury prevent systemic inflammation and can be immunosuppressive. Am J Respir Crit Care Med 163: 316-321, 2001.

17 Desborough JP: The stress response to trauma and surgery. Br J Anaesth 85: 109-117, 2000.

18 Baigrie RJ, Lamont PM, Kwiatkowski D, Dallman MJ and Morris PJ: Systemic cytokine response after major surgery. Br J Surg 79: 757-60, 1992.

19 Bone RC: Sir Isaac Newton, sepsis, SIRS, and CARS. Crit Care Med 24: 1125-1128, 1996.

20 Ware LB and Matthay MA: The acute respiratory distress syndrome. N Engl J Med 342: 1334-1349, 2000. 
21 Haga Y, Beppu T, Doi K, Nozawa F, Mugita N, Ikei S and Ogawa M: Systemic inflammatory response syndrome and organ dysfunction following gastrointestinal surgery. Crit Care Med 25: 1994-2000, 1997

22 Haga Y, Ikei S and Ogawa M: Estimation of Physiologic Ability and Surgical Stress (E-PASS) as a new prediction scoring system for postoperative morbidity and mortality following elective gastrointestinal surgery. Surg Today 29: 219-225, 1999.

23 American College of Chest Physicians/Society of Critical Care Medicine Consensus Conference: definitions for sepsis and organ failure and guidelines for the use of innovative therapies in sepsis. Crit Care Med 20: 864-874, 1992.

24 Dindo D, Demartines N and Clavien PA: Classification of surgical complications: a new proposal with evaluation in a cohort of 6336 patients and results of a survey. Ann Surg 240: 205-213, 2004.

25 Eisenhauer EA, Therasse P, Bogaerts J, Schwartz LH, Sargent D, Ford R, Dancey J, Arbuck S, Gwyther S, Mooney M, Rubinstein L, Shankar L, Dodd L, Kaplan R, Lacombe D and Verweij J: New response evaluation criteria in solid tumours: revised RECIST guideline (version 1.1). Eur J Cancer 45: 228247, 2009

26 McGill SN, Ahmed NA and Christou NV: Endothelial cells: role in infection and inflammation. World J Surg 22: 171-178, 1998.

27 Weiss SJ: Tissue destruction by neutrophils. N Engl J Med 320: 365-376, 1989.

28 Gando S: Microvascular thrombosis and multiple organ dysfunction syndrome. Crit Care Med 38: S35-42, 2010.

29 Grommes J and Soehnlein O: Contribution of neutrophils to acute lung injury. Mol Med 17: 293-307, 2011.

30 Sakamoto K, Arakawa H, Mita S, Ishiko T, Ikei S, Egami H, Hisano $\mathrm{S}$ and Ogawa M: Elevation of circulating interleukin 6 after surgery: factors influencing the serum level. Cytokine 6: 181-186, 1994.

31 Engelman E and Maeyens C: Effect of preoperative single-dose corticosteroid administration on postoperative morbidity following esophagectomy. J Gastrointest Surg 14: 788-804, 2010 .
32 Ono S, Tsujimoto H, Hiraki S, Takahata S, Kimura A, Kinoshita $\mathrm{M}$, Ichikura $\mathrm{T}$ and Mochizuki $\mathrm{H}$ : Effects of neutrophil elastase inhibitor on progression of acute lung injury following esophagectomy. World J Surg 31: 1996-2001, 2007.

33 Ono S, Aosasa S and Mochizuki H: Effects of a protease inhibitor on reduction of surgical stress in esophagectomy. Am J Surg 177: 78-82, 1999.

34 Tsujimoto $\mathrm{H}$, Ono $\mathrm{S}$, Ma Survival after neoadjuvant chemotherapy or chemoradiotherapy for resectable oesophageal carcinoma: an updated meta-analysis. Survival after neoadjuvant chemotherapy or chemoradiotherapy for resectable oesophageal carcinoma: An updated meta-analysis. jima T, Kawarabayashi N, Takayama E, Kinoshita M, Seki S, Hiraide H, Moldawer LL and Mochizuki H: Neutrophil elastase, MIP-2, and TLR-4 expression during human and experimental sepsis. Shock 23: 39-44, 2005.

35 Hirao M, Ando N, Tsujinaka T, Udagawa H, Yano M, Yamana $\mathrm{H}$, Nagai $\mathrm{K}$, Mizusawa $\mathrm{J}$ and Nakamura $\mathrm{K}$ : Influence of preoperative chemotherapy for advanced thoracic oesophageal squamous cell carcinoma on perioperative complications. $\mathrm{Br} \mathbf{J}$ Surg 98: 1735-1741, 2011.

36 Ruol A, Portale G, Castoro C, Merigliano S, Cagol M, Cavallin F, Chiarion Sileni V, Corti L, Rampado S, Costantini M and Ancona E: Effects of neoadjuvant therapy on perioperative morbidity in elderly patients undergoing esophagectomy for esophageal cancer. Ann Surg Oncol 14: 3243-3250, 2007.

37 Lin FC, Durkin AE and Ferguson MK: Induction therapy does not increase surgical morbidity after esophagectomy for cancer. Ann Thorac Surg 78: 1783-1789, 2004.

38 Kelsen DP, Ginsberg R, Pajak TF, Sheahan DG, Gunderson L, Mortimer J, Estes N, Haller DG, Ajani J, Kocha W, Minsky BD and Roth JA: Chemotherapy followed by surgery compared with surgery alone for localized esophageal cancer. N Engl J Med 339: 1979-84, 1998.
Received July 8, 2016

Revised August 23, 2016

Accepted August 26, 2016 